\title{
A produção textual de gêneros orais
}

\author{
The oral genres textual production
}

\author{
Adriana Beloti \\ Universidade Estadual do Paraná - UNESPAR \\ Cleber da Silva Luz \\ Universidade Estadual do Paraná - UNESPAR \\ DOI: https://doi.org/10.5902/2176148538737
}

\begin{abstract}
Resumo: Este artigo trata do que propõem os documentos norteadores do ensino de produção de textos para a disciplina de Língua Portuguesa - LP - e, posteriormente, apresenta uma caracterização de propostas de produção textual, de livros didáticos de 7 disciplinas do Ensino Médio, pautando-nos em Marcuschi (2008) e Travaglia (2013), acerca de aspectos do oral; e em discussões do Círculo de Bakhtin $(2011 ; 2018)$ sobre a perspectiva enunciativo-discursiva de linguagem. As análises revelam que os documentos apresentam idiossincrasias quanto à produção de textos com registro oral e, em consonância, as propostas das outras disciplinas desvalorizam o texto oral, reduzindo-o à atividade de oralização.
\end{abstract}

Palavras-chave: Produção textual. Gêneros orais. Linguagem enunciativo-discursiva.

Abstract: This paper is about what the teaching guiding documents propose for textual production in the Portuguese Language (LP) subject, and later, it presents a characterization of textual production proposals in textbooks of elementary school subjects. We based our study on Marcuschi (2008) and Travaglia (2013), about the oral aspects; and in the discussions of Bakhtin's Circle $(2011,2018)$ about the enunciative-discursive perspective of language. The analyzes reveal that the documents present idiosyncrasies regarding the production of texts in oral record, and in line with that, the proposals of the other disciplines devalue the oral text, reducing it into an activity of oralization.

Keywords: Textual Production. Oral Genres. Enunciative-Discursive perspective of language.

1 Este artigo é resultado de estudos realizados no Grupo de Pesquisa PRÁDIS - Práticas discursivas na escola (UNESPAR/CNPq). 
Adriana Beloti

Cleber da Silva

Luz

114
Quando se trata da produção de textos em situação de ensino e aprendizagem, comumente, vem à mente um texto escrito, pois está internalizada socialmente a compreensão de que o papel da escola é ensinar a linguagem na modalidade formal da língua e de que essa materializa-se apenas por gêneros discursivos com registro escrito. $O$ texto assim compreendido implica na desvalorização do gênero oral em detrimento do gênero escrito, como se houvesse uma hierarquização pela forma de registro. Nesse sentido, Baumgärtner $(2015$, p. 97) afirma que o “[...] fluxo de produção dos discursos produz regularidades nas práticas sociais de linguagem [e, desse modo, podem ser] materializadas em enunciados orais ou escritos".

Se o texto oral ainda encontra fatores de limitação para ser compreendido como um gênero do discurso que também cumpre determinadas finalidades, funções sociais e comunicativas e, assim, que precisa ser estudado nas escolas na disciplina de Língua Portuguesa - LP, haja vista o fato de que o principal objetivo de tal disciplina é o de trabalhar com o discurso como prática social e, portanto, com as suas várias possibilidades de materialização, formando os estudantes para agir socialmente nas mais diversas situações com as quais se deparam no mundo e no embate social, somos convocados a refletir, neste trabalho, como as práticas de escrita estão sendo compreendidas em outras disciplinas nas escolas, para além da LP, sobretudo no que diz respeito à oralidade ao identificarmos a enorme recorrência da prática de produção textual de gêneros orais.

Assim, propomos um estudo a respeito de práticas de escrita em diversas disciplinas do Ensino Médio na Educação Básica, a partir de encaminhamentos de produção textual apresentados pelos livros didáticos que dão suporte às ações pedagógicas dos professores em exercício nas salas de aula.

Para tanto, tecemos, primeiramente, considerações acerca da conceituação de gêneros do discurso estabelecendo especificidades dos gêneros orais com base em estudiosos do texto em perspectiva discursiva, no campo dos estudos da linguagem. Em seguida, procedemos com reflexões acerca do proposto para o trabalho com os gêneros discursivos na modalidade do registro oral e com a oralidade na sala de aula com suporte em documentos nacionais e estaduais que norteiam as práticas de ensino.

Por fim, analisamos os encaminhamentos de produção textual que apresentam gêneros discursivos da oralidade, identificados nos livros didáticos nas disciplinas de Biologia - BIOL, Filosofia - FIL, Física - FIS, Geografia - GEO, História - HIS, Química - QUÍM e Sociologia - SO- 
$\mathrm{CIOL}^{2}$, a fim de compreender qual concepção de produção textual de gêneros orais revelam, bem como se estabelecem as condições necessárias para que se produza discursos, a partir de gêneros orais, em determinadas situações enunciativas que pressupõem finalidades e interlocutores definidos. Muitas são as especificidades e este trabalho pode sinalizar que, em alguma medida, as práticas ainda tímidas e mal compreendidas na disciplina de Língua Portuguesa também têm seus reflexos no trabalho e na compreensão destes textos em outras disciplinas.

\section{Práticas pedagógicas de Língua Portuguesa e os gêneros orais}

A partir dos anos 90, com as discussões em torno da perspectiva discursiva de linguagem, ancorados em autores que consideram os pressupostos do Círculo de Bakhtin, a Linguística Aplicada no Brasil propõe que se adote como concepção de linguagem norteadora aquela que considera a língua como um processo de interação (DORETTO; BELOTI, 2011).

Nesse momento, o ensino de Língua Portuguesa é pautado em uma perspectiva que compreendia, conforme tratou Geraldi (1997), o texto, seja em modalidade oral ou escrita, como ponto de partida e ponto de chegada de todo processo de ensino e aprendizagem, em situação de leitura e produção. Daqui em diante, os textos são considerados como mobilizadores de discursos que revelam posicionamentos de um sujeito que enuncia de determinado lugar socialmente situado, pressupondo condições de produção estabelecidas para a sua produção no que se refere às situações de ensino e aprendizagem (MENEGASSI, 2016).

Essa conceituação emerge dos estudos de Bakhtin (2011, p. 262), quando o filósofo afirma ser particular e individual cada enunciado, mas “[...] cada campo de utilização da língua elabora seus tipos relativamente estáveis de enunciados [..]", os quais denominou gêneros do discurso. Nessa perspectiva, é necessário compreender que os gêneros do discurso são frutos de toda relação de interação verbal social e refletem as condições específicas de todos os possíveis campos de atividade humana de cada enunciado.

2 A escolha dessas disciplinas deu-se em decorrência de, entre os livros didáticas que compõem os corpora da pesquisa da qual oriunda este artigo, serem esses os que estão, atualmente, em uso na rede pública do Ensino Básico em uma cidade no noroeste do estado do Paraná e apresentarem práticas de produção textual de gêneros orais. 
Adriana Beloti

Cleber da Silva

Luz

116

Reside nesse conceito de gêneros discursivos uma das premissas para compreensão dos gêneros produzidos na modalidade oral como enunciados que permitem sistematização e são passíveis de serem estudados nas escolas, pois nas mais variadas relações sociais, em que os sujeitos interagem com seus interlocutores, gêneros orais podem ser utilizados e, assim como os escritos, possuem marcas típicas que estabelecem sua organização composicional, seu conteúdo temático e seu estilo de linguagem (BAKHTIN, 2011), sempre refletindo a finalidade de sua produção com vistas para o interlocutor a quem se produz o enunciado e a situação enunciativa. Em outras palavras, gêneros orais compreendem uma modalidade da língua e, uma vez que essa é nosso objeto de estudo e de ensino, é fundamental incorporá-los às práticas de ensino, a fim de compreender as funções que cumprem, atendendo a uma finalidade de realização do projeto de dizer em relação a um possível interlocutor do sujeito que interage por meio desse gênero.

Tal como o texto com registro escrito, o texto oral se materializa em diferentes gêneros discursivos, por meio de variados suportes, comportando diversos espaços de circulação, ao passo que revela o posicionamento do sujeito que o produz. Assim, a proposta para o ensino de línguas é que se paute não apenas nas formas de produção textual escrita, mas que se englobe como equivalente os gêneros orais. Raimo e Burach (2016) explicam que a oralidade, enquanto prática discursiva, tem ainda pouco espaço na sala de aula, pois ainda não há a compreensão por parte dos docentes de que essa prática envolve um trabalho complexo. Desconsideram-se, entre outros, os gêneros da fala cotidiana, mesmo sendo utilizados no dia a dia em reais situações de interação verbal social (RAIMO; BURACH, 2016).

Acerca dos aspectos que envolvem a oralidade em analogia à ideia de fala, Marcuschi e Dionisio (2007) afirmam que essa seria uma forma de produção textual discursiva oral e, por sua vez, dispensa a necessidade de um aparato tecnológico ${ }^{3}$ além do próprio ser humano. Ainda assim, embora pareça algo simples sem sistematização, os autores propõem que se compreenda a complexidade desse fenômeno tal como a do texto escrito, considerando o fato de que, em situações particulares, a oralidade assume-se e funda-se como uma prática altamente

3 A essa expressão os autores pretendem estabelecer uma relação ao que chamamos de suporte textual, pois em práticas de produção textual escrita o texto concretiza-se em diferentes materialidades, como as folhas de caderno, sulfites ou, então, por meio de computadores e outros equipamentos eletrônicos. 
desenvolvida, como, por exemplo, em situações de discursos políticos em público ou de uma entrevista de emprego em uma grande multinacional do ramo de investimentos (MARCUSCHI; DIONISIO, 2007). A essa complexidade do gênero, em maior ou menor grau, estão atreladas as condições de produção em que o texto acontece, ou seja, qual a finalidade, quem são os interlocutores e qual o gênero que mobilizará tal discurso, sendo, desse modo, a situação enunciativa o que determina o gênero a ser produzido e seu estilo e organização próprios.

$\mathrm{Na}$ esteira dessas discussões, Travaglia [et al] (2013) propõe estabelecer a conceituação e a caracterização dos gêneros orais ${ }^{4}$. Segundo o autor, embora o conceito pareça óbvio, não o é. Assim, é importante que se compreenda, considerando as assertivas de Marcuschi (2008), que o fato de oralizar um texto escrito não o torna um gênero oral, pois o

\section{A produção textual de gêneros orais} que se deve compreender são as marcas típicas fundamentais que dão o todo do acabamento do enunciado em função da finalidade que cumpre (BAKHTIN, 2011). Portanto, um texto oral que tem o escrito em sua origem, simplesmente por ser oralizado, não significa que seja um gênero oral, com todos os aspectos que tal conceito recupera, levando-nos à compreensão de que são, de fato, os elementos discursivos, ou seja, as finalidades e funções sociais e comunicativas, próprias de cada situação de interação verbal social, que demandam os textos adequados, isto é, se orais ou escritos.

Segundo Travaglia [et al] (2013, p. 4), os gêneros orais são aqueles que têm como suporte a voz humana “[...] e que foi produzido para ser realizado oralmente, utilizando-se a voz humana, independentemente de ter ou não uma primeira versão escrita.". Contudo, também podemos considerar gêneros orais aqueles que têm uma versão primeira escrita, mas têm em vista uma realização prioritariamente oral, como é caso, por exemplo, da palestra. Esse gênero, por sua vez, compreende uma organização daquilo que será dito, em primeira instância com registro escrito, mas sua função social é cumprida por meio da oralização, pois a situação enunciativa em que é produzido pressupõe a materialização por meio da voz.

4 Em Gêneros orais - conceituação e caracterização, texto produzido por Luiz Carlos Travaglia a partir de discussões com colegas-pesquisadores do grupo de pesquisa PETEDI, coordenado também pelo autor, são apresentadas discussões sobre o gênero fundamentadas nas Teorias da Linguística Textual e outras Teorias do Discurso, essa última, majoritariamente, sob o viés dos estudos do Círculo de Bakhtin. Por esse motivo consideramos as concepções que são apresentadas no texto, uma vez que este trabalho também se fundamenta na concepção de linguagem enunciativo-discursiva de orientação bakhtiniana. 
Adriana Beloti

Cleber da Silva

Luz

118

A partir dessa conceituação, o autor ([et al] 2013) propõe algumas dos possíveis campos de circulação dos gêneros orais, a fim de que sejam compreendidos enquanto gêneros discursivos de ampla circulação social, como, por exemplo: a) esferas de relação do dia a dia: gênero Conversa; b) esferas do entretenimento e literária: gênero Cantiga de Roda; c) esferas escolar e acadêmica: gênero Debate de Opinião; d) esferas religiosas: gênero Sermão; entre outras.

Até aqui tecemos discussões acerca dos gêneros do discurso e como são considerados no processo de ensino e aprendizagem nas escolas. Assim, passamos pela compreensão de gênero do discurso como um enunciado que incorpora discursos de sujeitos situados histórica e socialmente e que pressupõem uma relação de interação verbal social, para, a partir disso, refletirmos sobre os gêneros da modalidade oral e algumas de suas características.

Posto isso, procedemos com a análise de alguns documentos nacionais e estaduais, a fim de compreender como esses gêneros estão sendo discutidos no que se refere à sua inserção nas práticas discursivas de produção textual, bem como à sua relação com o conceito de oralidade, uma vez que, nos estudos da linguagem, temos a oralidade enquanto um dos eixos fundantes das práticas de ensino e aprendizagem de Língua Portuguesa.

\section{Documentos norteadores do processo de ensino e aprendizagem: gêneros orais e oralidade}

O ensino e a aprendizagem em todas as áreas na Educação Básica tem como norte documentos oficiais que orientam as práticas pedagógicas, os conteúdos, incluindo procedimentos metodológicos, levando em consideração o que se espera que os estudantes aprendam ao final de cada ano ou nível de ensino. Há documentos a nível nacional, como os Parâmetros Curriculares Nacionais - PCN (BRASIL, 1998), e a nível estadual, como o estado do Paraná que apresenta as Diretrizes Curriculares Estaduais - DCE (PARANÁ, 2008), para todas as disciplinas contempladas pela Rede Básica de Ensino.

Assim, ao considerarmos que todas as práticas de ensino realizadas em sala de aula têm como ponto de partida documentos que preveem o que e como deve ser trabalhado nas escolas, tomamos alguns desses documentos, também, como objeto de análise para tecermos reflexões acerca do trabalho com a linguagem, no trato com a produção textual, enfocando aqui, especificamente, a prática de produção textual 
de gêneros orais. Partimos do pressuposto de que todas as disciplinas, ao trabalharem com textos, estão também trabalhando com linguagem e é nesse sentido que esta pesquisa debruça-se sobre essas práticas, a fim de observar como acontecem nas escolas, buscando ampliar as discussões, da perspectiva de estudiosos da Linguística Aplicada, para disciplinas diversas da de Língua Portuguesa.

A despeito disso, nesta seção, consideramos as discussões dos documentos para a disciplina de Língua Portuguesa, pois nosso objetivo é centralizar as discussões acerca das práticas com o texto oral. Assim, para apresentarmos de modo mais sistemático como os documentos tratam das propostas para as práticas de produção de textos orais, tomaremos como ponto de partida os documentos específicos de Língua Portuguesa, uma vez que essa disciplina é, em essência, a que trabalha com a linguagem e, logo, cujos documentos delimitam encaminhamentos para tal prática.

Os PCN para a disciplina de Língua Portuguesa para os terceiro e quarto ciclos do Ensino Fundamental (BRASIL,1998, p. 41) já sinalizam essa preocupação com o trabalho que é realizado com a linguagem também nas demais disciplinas, pois afirmam que "[...] dada a importância para o trabalho da linguagem na mediação do conhecimento é atribuição de todas as áreas, e não só de Língua Portuguesa, o trabalho com a escrita e a oralidade do aluno [...]. Assim, compreendemos que, ao tratar de seus conteúdos específicos, todas lidam com a linguagem, seja ela oral ou escrita.

São necessárias as discussões acerca do trato com a linguagem oral nas escolas, sobretudo na prática de escrita, pois o que percebemos, em muitos momentos, é que a oralidade restringe-se, enquanto conteúdo de ensino, às aulas de variação linguística. Isso se observarmos a disciplina de Língua Portuguesa, pois, em contrapartida, nas demais disciplinas esse não é um conteúdo contemplado como integrante das práticas de ensino.

Tal aspecto fica acentuado ao observamos que os PCN - LP para os terceiro e quarto ciclos do Ensino Fundamental (BRASIL, 1998, p. 82) discutem ser importante que o estudante, ao aprender novas formas linguísticas, "[...] particularmente, a escrita e a padrão de oralidade mais formal, orientada pela tradição gramatical, entenda que todas as variedades linguísticas são legítimas e próprias de cultura e de história humana.". Nesse limiar, o documento discorre, dando sequência, que devem ser trabalhados, inseridos ao conteúdo de variação linguística, textos de registro oral. 
Adriana Beloti

Cleber da Silva

Luz

120

Ao tomarmos o trecho citado, observamos que o documento ainda apresenta uma concepção que prioriza, em situação de ensino, o que é estabelecido pela gramática tradicional. Isso, em alguma medida, pode estar atrelado ao fato de que, conforme propõem (BRASIL, 1998), as crianças já dominam a linguagem oral e a escola, para muitos, é o único lugar que pode possibilitar acesso aos textos escritos. Essas crianças, por sua vez, tendem a produzir textos com base em estratégias de organização típicas da oralidade, mesmo quando têm acesso aos textos escritos, devido ao contato não escolarizado apenas com a língua falada.

Há que observar, nesse sentido, a incompreensão do papel da escola no trabalho com a linguagem, uma vez que, afirmar que os estudantes já chegam às escolas dominando a linguagem oral não é a maneira mais adequada de se referir a tal forma de registro de linguagem que a criança já conhece e usa até chegar à escola. Todos, antes de frequentar a escola - responsável pela sistematização do ensino formal -, dominam algumas modalidades da linguagem, que, predominantemente, é oral, mas pode ser em algumas formas de escrita, também. Ou seja, já conhecem e sabem utilizar, de acordo com as situações já experienciadas, algumas variedades linguísticas e é, justamente, a partir das práticas realizadas em sala de aula, que o estudante aprenderá outras variedades, no caso, especialmente, as mais formais, tanto de registro escrito, quanto oral, considerando todos os fatores que envolvem as mais diversas situações de interação verbal social, sobretudo no que diz respeito à adequação à situação enunciativa e ao interlocutor.

Compreendemos, a partir dessa breve exemplificação, que a prática de trabalho com textos orais tende a ser mero reconhecimento do texto oral como possível de marcar, linguisticamente, variantes que podem ser regionais, de idade, entre outros condicionadores. Não há a compreensão desses textos como gêneros discursivos com circulação ampla, mas sim de um "texto-menor", não valorado, nos campos de atividade humana e, por sua vez, de interação verbal social. Acreditamos que possa emergir de práticas como essas a compreensão de que textos escritos tendem para o registro formal da língua, enquanto textos orais não comportam esse registro. Não há, portanto, a compreensão de contexto específico de interação por meio da linguagem como elemento determinante do gênero discursivo a ser produzido 
Já os PCN para o Ensino Médio (BRASIL, 2000) apresentam uma compreensão mais ampla de trabalho com a prática de produção textual de gêneros orais e escritos, pois afirmam que:

\begin{abstract}
A linguagem verbal, oral e escrita representada pela língua materna ocupa, na área, o papel de viabilizar a compreensão e o encontro dos discursos utilizados em diferentes esferas da vida social. É com e pela língua que as formas sociais e arbitrárias de visão e divisão de mundo são incorporadas e utilizadas como instrumentos de conhecimento e comunicação. [Assim] [...], o desenvolvimento da competência linguística do aluno do Ensino Médio, dentro dessa perspectiva, não está pautado na exclusividade do domínio técnico de uso da língua legitimada pela norma
\end{abstract}

A produção textual de gêneros orais

A compreensão da prática de produção textual, marcando a produção do texto oral não como menor ou secundário, mas como igual ao escrito, neste documento atende ao que propõem os estudos da linguagem quando se referem à produção de textos. Ao serem considerados na perspectiva encunciativo-discursiva de linguagem, que se ancora nos pressupostos do Círculo de Bakhtin, são caracterizados como formas tipicamente organizadas socialmente (BAKHTIN, 2011) por meio das relações sociais correntes que podem variar devido a sua condição de estável, considerando as mudanças que ocorrem na sociedade ao longo dos tempos e que a linguagem as acompanha por ser, também, constituída a partir dessas relações.

Os gêneros do discurso, no seio da sociedade, organizam-se em decorrência das funções sociais que cumprem, dando condições aos sujeitos de serem autores de seu discurso realizando seu projeto de dizer (BAKHTIN, 2011). Nesse sentido, o documento apresentado revela a compreensão de que texto é o lugar em que ocorre a interação entre sujeitos na sociedade. Assim, deixa-se de lado a concepção de uso da língua determinado pela gramática tradicional, por conceber que a ora- 
Adriana Beloti

Cleber da Silva

Luz

lidade, nas escolas, não é apenas para ensinar aos alunos a "falar bem", mas, sim, para agir socialmente por meio das infinitas possibilidades de gêneros orais que atendem a propósitos estabelecidos ou, ainda, as possibilidades que estão a surgir socialmente.

Assim, o documento para o Ensino Médio já apresenta uma discussão mais ampla e adequada à finalidade do trabalho com os gêneros orais em práticas de produção de textos nas escolas. Produzir texto é produzir discurso e discurso cumpre funções na vida dos sujeitos, servem a atender determinados propósitos de interação. E é esse um dos motivos para que se compreenda os gêneros orais como mobilizadores de posicionamento, assim como textos escritos, e não inferiores a estes.

Um exemplo seria pensar que um bilhete para sua mãe, deixado na geladeira, embora escrito, tende a materializar-se em linguagem bastante informal, pois comporta a finalidade que seria a de deixar um recado rápido, o interlocutor, que seria a sua mãe, e a situação ampla de circulação, que seria a sua casa. Em contrapartida, a palestra, gênero materializado pela oralidade, mesmo que possa ser precedido de uma versão escrita, tende a ser produzido considerando um estilo de linguagem mais formal, adequando-se à finalidade a qual se destina, ao interlocutor estabelecido pela própria situação e, portanto, a toda situação mais ampla de enunciação.

As DCE para a disciplina de Língua Portuguesa (PARANÁ, 2008) levantam a discussão das práticas de trabalho com a oralidade nas escolas. De acordo com o documento, tais práticas pautam-se na ideia comum de que toda criança domina a oralidade. Em alguma medida, essa acepção leva ao fato de que práticas tão comuns ao dia a dia, podendo ser considerada a mais utilizada por meio da fala, sejam desconsideradas como passíveis de ensino e sistematização, pois não há a compreensão de que essas práticas constituem-se a partir de finalidades e funções sociais e comunicativas que se concretizam a partir de gêneros discursivos, corroborando com a assertiva de Bakhtin (2011) de que todo sujeito, ao fazer uso da língua, a partir de possiblidades que lhe são oferecidas por ela, está produzindo gêneros discursivos, que não são meros aparatos estruturais, mas mobilizadores de funções específicas.

Refletindo sobre o ambiente escolar, compreendemos que a prática de produção de textos exercita-se, quase em totalidade, por meio da linguagem escrita, fazendo com que, assim, a linguagem oral não seja valorizada em alguns contextos educacionais (PARANÁ, 2008). “Entretanto, 
é rica e permite muitas possibilidades de trabalho a serem pautadas em situações reais de uso da fala e produção de discursos nos quais o aluno se constitui como sujeito do processo interativo" (PARANÁ, 2008, p. 55).

Assim, observamos que, embora os documentos apresentem a prática de produção textual oral e apontem para algumas preocupações acerca de sua abordagem na sala de aula, em algumas situações, o trabalho com a oralidade recai, meramente, no ensino de variedades linguísticas, sem inserir o texto em um campo amplo de circulação social para que seja compreendido enquanto gênero discursivo. Em outros momentos, podemos compreender os gêneros orais como instrutores do falar bem, pois os documentos demonstram que a oralidade nas escolas serve para que ensinar ao aluno a "falar corretamente", distanciando-o da oralidade que conhece e utiliza anteriormente a escola.

A produção textual de gêneros orais

A partir dessas constatações, propomos analisar como as práticas de produção textual oral caracterizam-se em outras disciplinas que não a de LP. Esse questionamento e outros motivam nossas discussões na seção seguinte deste trabalho.

\section{Concepções e práticas de produção de gêneros orais em disciplinas do Ensino Médio}

Geraldi (1997) explica que para produzir um texto, em qualquer modalidade (oral ou escrito), é necessário que se tenha condições para a realização dessa prática. A partir disso, Menegassi (2016) propõe que as condições de produção em que o texto é solicitado são responsáveis pelo atendimento ou não ao estabelecido pelo comando de produção textual. Com esse entendimento, faz-se necessário compreender que nos comandos de produção textual deverão ser marcados: a) finalidade; b) interlocutor; c) gênero discursivo; d) circulação social; e) suporte textual; f) posicionamento do autor (MENEGASSI, 2011). Às práticas de produção textual escrita que consideram o processo, tendo estabelecidas tais condições, Fiad e Mayrink-Sabinson (1991) denominou práticas de escrita como trabalho. Além disso, conceber a escrita como trabalho implica, também, compreender que essa acontece em etapas, considerando o planejamento, a execução, a revisão e a reescrita do texto, ao passo que, ao final, é avaliado o processo e não o produto (MENEGASSI, 2016).

Assim como são produzidos gêneros escritos, gêneros orais comportam as mesmas condições de produção, pois, conforme tratou Geraldi (1997), a produção de textos é entendida desse modo, seja 
Adriana Beloti

Cleber da Silva

Luz

ao produzir textos com registro escrito, seja com registro oral. Nesse sentido, para avaliar como essas condições de produção são dispostas para o trabalho com os textos nas demais disciplinas que são objeto de estudo desta pesquisa, analisamos as propostas de produção textual quanto aos seguintes aspectos: a) finalidade; b) interlocutor, especificamente o virtual; c) gênero discursivo. Os demais elementos não são tomados como objeto de análise, aqui, devido ao fato de que, geralmente, se apresentam de maneira já delimitada pela situação enunciativa pré-determinada pelo contexto escolar. Ao sistematizar as análises de tais elementos, produzimos o Quadro 1, que apresenta a sistematização, conforme segue:

Quadro 1: Condições de produção estabelecidas nas propostas de produção

\begin{tabular}{|c|c|c|c|c|c|c|}
\hline \multirow{2}{*}{ Disciplina } & \multirow{2}{*}{$\begin{array}{c}\text { Quantidade } \\
\text { de propostas }\end{array}$} & \multicolumn{2}{|c|}{ Elementos das condições de produção nas propostas } \\
\cline { 3 - 7 } & & \multicolumn{2}{|c|}{ Finalidade } & Interlocutor & \multicolumn{2}{|c|}{ GD } \\
\cline { 3 - 7 } & & Marcada & Inferida & virtual & Marcado & Inferido \\
\hline BIOL & 9 & 3 & 6 & 1 & 2 & 7 \\
\hline FIL & 17 & 5 & 12 & 0 & 0 & 17 \\
\hline FIS & 1 & 0 & 1 & 0 & 0 & 1 \\
\hline GEO & 3 & 0 & 3 & 0 & 0 & 3 \\
\hline HIS & 16 & 0 & 16 & 0 & 0 & 16 \\
\hline QUÍM & 3 & 2 & 1 & 0 & 2 & 1 \\
\hline SOCIOL & 10 & 3 & 7 & 2 & 2 & 8 \\
\hline Total Geral & $\mathbf{5 9}$ & $\mathbf{1 3}$ & $\mathbf{4 6}$ & $\mathbf{3}$ & $\mathbf{6}$ & $\mathbf{5 3}$ \\
\hline
\end{tabular}

Fonte: Os pesquisadores.

A partir dos dados expostos no Quadro 1, observamos, primeiramente, a finalidade das produções, pois ter uma razão para dizer aquilo que vai dizer é uma das principais condições a serem estabelecidas para uma produção textual (GERALDI, 1997), visto que é o primeiro elemento necessário para o estabelecimento do projeto de dizer. Assim, antes que se pense nos demais elementos, é necessário que o aluno tenha delimitada qual é a finalidade da sua produção. Das 59 propostas analisadas, conforme a quantidade específica de cada disciplina disposta no Quadro 1, apenas 13 apresentam a finalidade demarcada no comando de produção, sendo 3, 5, 2 e 3 das disciplinas de BIOL, FIL, QUÍM e SOCIOL, respectivamente. 
Em contrapartida, 46 propostas apresentam a finalidade da produção de modo que precisa ser apreendida por meio de inferência nos comandos de produção. Estes números se dividem entre as disciplinas de BIOL, FIL, FIS, GEO, HIST, QUÍM e SOCIOL com 6, 12, 1, 3, 16, 1 e 7 ocorrências, nessa sequência. A marcação da finalidade da produção de modo implícito leva-nos a refletir acerca das discussões de Silva (2018), quando afirma que, em algumas situações de produção de textos ${ }^{5}$, alguns elementos das condições de produção podem vir marcados por meio de palavras ou inferidos pelo contexto, fazendo com que o elemento recuperado por inferência não seja marcado linguisticamente. Exemplificando, a autora (2018) explica que verbos como "expor", "argumentar" e "relacionar" podem estabelecer a finalidade de uma produção textual que não a marque linguisticamente, denominado esses verbos como de

A produção textual de gêneros orais

\section{Exemplo 1 - Finalidade inferida por verbo de finalidade}

"Discuta com seus colegas os problemas sociais responsáveis pelas tragédias que ocorrem por ocasião dos desabamentos, como a morte de muitas pessoas e a perda de bens materiais" (destaque nosso).

Fonte: Almeida (2013, p. 105).

No Exemplo 1, a finalidade ${ }^{6}$ dessa produção, ainda que não marcada linguisticamente (“a finalidade da produção é discutir..."), pode ser inferida por meio do verbo "discuta", cujo propósito, então, é que o estudante discuta com os colegas acerca dos problemas sociais que são causados em decorrência de desabamentos. Ainda assim, partimos da análise apenas do enunciado escrito e não de uma prática em sala de aula, ressaltamos que, em determinados contextos, se o professor não intervir com a leitura do comando de produção e enfatizar a finalidade da proposta, o aluno, em alguns casos, pode não alcançar o grau de in-

5 A pesquisa da autora (2018) toma como objeto para as reflexões o contexto de Prova de Redação em situação de Concurso Vestibular, contudo, aproximamos as discussões visto que as ocorrências permitem-nos estabelecer tal relação.

6 Consideramos, aqui, a finalidade como distinta do objetivo da produção. Em nossa acepção, a finalidade é contemplada pela função social que o discurso produzido cumpre. Em contrapartida, o objetivo cumpre o aspecto material da produção, ou seja, contempla a situação, ora avaliativa, ora de aparato metodológico para a prática pedagógica que o professor desenvolve na situação de ensino. Importante considerar, ainda, que estabelecer a finalidade da produção, por sua vez, também se difere da finalidade do gênero, uma vez que essa, delimitada a priori pela composição tipicamente organizada, pode variar, a posteriori, em decorrência da situação enunciativa em que um determinado projeto de dizer é produzido. 
Adriana Beloti

Cleber da Silva

Luz

126

ferência necessário para compreender o que está sendo proposto, dado que essa inferência demandaria do estudante um conhecimento prévio sobre tal prática, o que não podemos afirmar que o estudante possui.

No que concerne ao interlocutor virtual (MENEGASSI, 2016), compreendemos que tem papel importante na produção dos textos dos estudantes, uma vez que, se considerarmos a situação hipotética que é criada, muitas vezes, para produzir textos que não pertencem às esferas escolar e acadêmica, é a imagem do interlocutor virtual que precisa ser considerada para a produção do texto, visto que os interlocutores real e o superior, na situação de ensino, em sala de aula, serão sempre o professor e a instituição escolar, respectivamente.

Nesse sentido, é possível observar que as práticas de produção textual em outras disciplinas não dão estas condições na medida em que, como podemos observar no Quadro 1, apenas 2 propostas de BIOL e 1 de SOCIOL estabelecem esse tipo de interlocutor no encaminhamento, entre o total de 59. Isso pode, em alguns casos, ocasionar o não atendimento à proposta de produção uma vez que o estudante produzirá seu texto sempre para o professor que, em outra situação, arquitetada hipoteticamente para pensar uma situação real de uso da linguagem, não é o interlocutor para o qual se produz o texto.

No que diz respeito ao gênero discursivo delimitado para a produção, observamos que é marcado no comando em 6 propostas, sendo 2 em BIOL, 2 em QUÍM e 2 em SOCIOL, das 59 analisadas. Já nas outras 53 propostas, o gênero discursivo pode ser inferido em 7 da disciplina de BIOL, 17 de FIL, 1 de FIS, 3 de GEO, 16 de HIS, 1 de QUíM e 8 de SOCIOL. À possibilidade de inferência da marcação dos gêneros, associamos o fato de não serem estabelecidos linguisticamente, pelo proposto no comando ser determinado por meio de verbos, assim como o de finalidade conforme pondera Silva (2018). Assim, depreendemos, aqui, que essa inferência aconteça por meio da marcação de verbos que introduzem gênero. Observamos o exemplo 2:

Exemplo 2: Gênero discursivo inferido por verbos que introduzem gênero "Pesquise sobre reality shows na televisão brasileira e depois debata com os colegas as questões a seguir, registrando em seu caderno as conclusões a que chegaram. [...]" (destaque nosso).

Fonte: Vasconcelos (2016, p. 175). 
Embora não seja possível identificar a marcação de um gênero de maneira explícita, acreditamos que a presença do verbo debater, no imperativo, permita a inferência de que a produção ocorrerá por meio de um Debate, gênero oral tipicamente pertencente à esfera acadêmica e escolar (TRAVAGLIA [et al], 2013). Desse modo, defendemos a ideia de que há a possibilidade de reconhecimento do gênero proposto a partir dos verbos que permitem a recuperação da finalidade. Ainda assim, essa inferência pode ser possível a partir do conhecimento que se tem sobre o gênero discursivo em questão, e, em consequência, de sua função social, mesmo que de maneira não escolarizada.

o gênero Debate, por exemplo, pode ser conhecido pelo estudante por ouvir alguém falar ou ver na televisão, em determinadas épocas, sobre debates que acontecem entre sujeitos, em situações

A produção textual de gêneros orais específicas. Contudo, o estudante pode não ter um conhecimento de que essa ação que se desenvolve num Debate seja uma produção textual de um gênero discursivo com registro oral. Nesse sentido, ressaltamos que, se a prática não for corriqueira ou se, por exemplo, ao produzir o comando o professor não adeque as escolhas lexicais à proposta, mais uma vez o estudante pode não entender por inferências necessárias para produzir o texto de acordo com o que é proposto pelo comando de produção.

Até aqui, buscamos compreender como se dá o estabelecimento de condições de produção para as práticas de produção textual, considerando que toda modalidade de produção textual, seja oral ou escrita, pressupõe como ponto de partida condições necessárias para esse fim, e são assim compreendidas por se ancorar na perspectiva enunciativo-discursiva de linguagem que concebe o texto como um trabalho processual (FIAD; MAYRINK-SABINSON, 1991). Quanto às práticas de produção textual oral, os PCN - LP (BRASIL, 1998) definem as seguintes atividades para sua produção:

\footnotetext{
- Planejamento prévio da fala em função da intencionalidade do locutor, das características do receptor, das exigências da situação e dos objetivos estabelecidos;

- Seleção, adequado ao gênero, de recursos discursivos, semânticos e gramaticais, prosódicos e gestuais;

- Emprego de recursos escritos (gráficos, esquemas, tabelas) como apoio para a manutenção da continuidade da exposição;
} 
- Ajuste da fala em função da reação dos interlocutores, como levar em conta o ponto de vista do outro para acatá-lo, refutá-lo ou negociá-lo (BRASIL, 1998, p. 58, destaques nossos) ${ }^{7}$.

Assim, compreendemos que as práticas discursivas de produção textual consideram especificidades do contexto, interlocutores e finalidades da produção adequando-se ao proposto para a realização

Adriana Beloti

Cleber da Silva

Luz

no registro oral. A partir das análises que revelaram as condições de produção em que são propostas as práticas de produção textual e conforme os pressupostos teórico-metodológicos discutidos nas duas seções anteriores deste trabalho, identificamos algumas especificidades que implicam em concepções do texto oral e de sua produção. Desse modo, apresentamos o Quadro 2 com a sistematização das concepções e características da produção textual oral identificadas com fundamento nas análises:

\section{Quadro 2: Princípios e principais características dos gêneros orais}

\begin{tabular}{|l|l|}
\hline \multicolumn{1}{|c|}{ Princípios } & \multicolumn{1}{c|}{ Principal características } \\
\hline $\begin{array}{l}\text { 1. Gênero oral como infe- } \\
\text { rior ao escrito }\end{array}$ & $\begin{array}{l}\text { - Produz-se com registro escrito um gênero tipicamente } \\
\text { oral }\end{array}$ \\
\hline $\begin{array}{c}\text { 2. Gênero oral como "orga- } \\
\text { nizador de ideias" }\end{array}$ & - Precede uma produção de gênero com registro escrito \\
\hline $\begin{array}{c}\text { 3. Gênero oral como ativi- } \\
\text { dade de exercício da fala }\end{array}$ & - Oralização de gêneros com registro escrito \\
\hline 4. Atividade oral & - Produção com registro oral sem as condições necessárias \\
\hline $\begin{array}{l}\text { 5. Prática discursiva de } \\
\text { produção textual oral }\end{array}$ & $\begin{array}{l}\text { - Compreende as especificidades do gênero oral, propor- } \\
\text { cionando as devidas condições para sua produção }\end{array}$ \\
\hline
\end{tabular}

Fonte: Os pesquisadores.

Analisando as propostas de produção textual para gêneros orais presentes nos livros didáticos, identificamos que, das 59 propostas, 11 se vinculam ao princípio 1, 20 no princípio 2, 2 no princípio 3, 24 no prin-

7 Os termos em destaque, em nossa avaliação, revelam uma concepção estruturalista de produção textual, ainda priorizando os elementos do sistema de comunicação, que atendem à concepção de linguagem como instrumento de comunicação. Nessa concepção, a interação não se instaura, de modo que a produção apenas depende da intencionalidade do locutor, que tem um objetivo e lança sua mensagem em direção a seu locutor que a recebe e capta, tal como foi endereçada. Não se considera a situação de interação entre sujeito produtor e locutor, com a mesma importância, deixando de lado, também, a finalidade da produção. 
cípio 4 e 2 no princípio 5. Apresentamos, na sequência, alguns comandos de produção correspondentes aos princípios sistematizados, a fim de exemplificar cada concepção e suas características.

Exemplo 3: Comando de produção da disciplina de FIL - princípio 1

"Após refletir sobre as características da concepção aristotélica de ciência e as características da ciência moderna, escreva um diálogo entre uma pessoa defendendo a ciência de Aristóteles e outra defendendo o modelo de ciência de Bacon e Galileu." (destaque nosso)

A produção

Fonte: Vasconcelos (2016, p. 191).

textual de

gêneros orais

Para esta produção, o estudante irá pensar um possível diálogo entre duas pessoas e apresentar um texto escrito que transcreva as falas. É importante destacar que, embora se trate de um gênero com possibilidade de ser produzido, de fato, em registro escrito, esse, por sua vez, pertence, em primeira instância, à oralidade, até porque um "diálogo escrito" já pressupõe outros gêneros, em suportes específicos, como chat online, mensagens por aplicativos. Assim, nota-se uma desvalorização da oralidade em detrimento da escrita, uma vez que, mesmo propondo um trabalho que possibilita abordar um gênero oral, não o é explorado, especificamente, quanto aos aspectos do texto oral.

Exemplo 4: Comando de produção da disciplina de GEO - princípio 2 "1. reúnam-se em duplas para pesquisar as hidrelétricas que estão sendo construídas no rio Madeira. Durante a pesquisa, procurem obter dados para promover em classe uma discussão sobre os impactos ambientais que a construção dessas usinas pode causar nas comunidades próximas.

2. depois de debaterem sobre os impactos ambientais locais, as duplas devem escrever um texto dissertativo a respeito dos motivos que levariam nações a entrar em conflito pela posse de água ou pela escassez desse recurso." (destaque nosso) Fonte: Almeida (2013, p. 172).

Nessa proposta, observamos a ideia de um passo-a-passo para o desenvolvimento da produção. No passo 1, os estudantes deverão fazer uma pesquisa e, em seguida, realizar um Debate com a discussão dos dados levantados pelas pesquisas. Na segunda etapa, após debaterem as ideias, devem produzir um texto dissertativo, como produto final dessa atividade. Assim, fica evidente que, a partir dos conteúdos pesquisados, a 


\section{Adriana Beloti}

Cleber da Silva

Luz discussão oral, produzida por meio do Debate, acontece anterior ao momento do registro escrito em função de organizar as ideias por meio fala, sistematizando o que vai ser dito, a partir das discussões, no texto escrito.

Exemplo 5: Comando de produção da disciplina de BIOL - princípio 3 "Em grupo, selecionem cinco notícias de jornais e revistas impressos ou de sites confiáveis na internet que, para serem compreendidos, requeiram conhecimentos básicos de Biologia. Se possível, peçam orientação ao professor de Língua Portuguesa com relação a grandes jornais e revistas que geralmente publicam matérias com conteúdo científico.

Depois, apresentem um resumo de uma dessas notícias para a classe, argumentando porque esse tipo de conhecimento é importante." (destaque nosso).

Fonte: Linhares (2016, p. 24).

O comando apresentado pela disciplina de Biologia propõe que os estudantes realizem pesquisas e, a partir disso, produzam um Resumo para apresentar à classe. No comando, não é marcada a ideia de que se produz primeiramente por escrito, mas sim, que após as pesquisas o apresentem à turma. Essa proposta evidencia uma prática que atende à concepção de que um gênero oral opera como exercício da fala, pois, nesse contexto, produz-se um gênero escrito, em formato oralizado. Não há uma função para oralizar o texto, além da de exercitar a fala, uma vez que esse gênero cumpre sua função social e comunicativa por meio da escrita.

Exemplo 6: Comando de produção da disciplina de FIS - princípio 4 "Discuta: em que medida seria possível obter o equivalente mecânico do calor fazendo a conversão em sentido contrário?" (destaque nosso)

Fonte: Yamamoto (2013, p. 211).

Nesse exemplo, observamos que a proposta de atividade oral caracteriza-se como uma produção, pois propõe que seja feita uma discussão, verificado por meio do verbo discutir no imperativo (discuta). Ainda assim, não há a marcação de nenhuma condição de produção nem de estratégias que possam orientar a produção textual do aluno. Práticas como essa tendem a ser apenas compreendidas como "falar" (oralmente) sobre determinado conteúdo. 
Exemplo 7: Comando de produção da disciplina de QUÍM - concepção 5 "A sala pode ser dividida em dois grupos, I e II, para debater o seguinte problema: sabe-se que as dioxinas afetam o sistema imunológico, o funcionamento da tireoide e do fígado, gerando maior suscetibilidade a infecções. Exposições a elevadas concentrações foram associadas a problemas congênitos, atraso no crescimento de crianças, alterações hormonais, alteração na razão de nascimentos entre machos e gêmeas, diabetes e câncer. A única forma de banir as dioxinas seria uma transição de materiais e processos livres de cloro. Isso é viável? Grupo I deve pesquisar argumentos para provar que é viável a transição para materiais e processo livres de cloro.

Grupo II deve pesquisar argumentos para provar que não é viável a transição para materiais e processos livres de cloro." (destaque nosso)

A produção textual de gêneros orais

Fonte: Fonseca (2016, p. 235).

O exemplo 7 apresenta o comando de produção da disciplina de Química, a partir do qual percebemos como se caracteriza uma prática discursiva de produção textual oral. Nele, é possível identificar a finalidade "debater acerca do problema das dioxinas", com interlocutores estabelecidos, os estudantes terão os colegas da sala do grupo adverso, assim como o professor que media e participa como interlocutor e coautor da produção. Imbricada à situação enunciativa, a circulação social da produção será a sala de aula, o suporte textual, a voz dos estudantes e o posicionamento social será de estudante do $1^{\circ}$ ano do Ensino Médio, podendo assim ser compreendidas a partir da situação extraverbal (VOLOCHINOV/BAKHTIN, 1926).

Além da marcação destes elementos, o Debate pressupõe dois pontos de vista em que cada grupo argumenta defendendo seu posicionamento. Essa orientação é considerada e apresentada nos dois tópicos finais do comando de produção, quando propõe que um grupo defenda as medidas como viáveis e, o outro, como inviáveis. Desse modo, compreendemos que, além de marcar os elementos das condições de produção, a proposta está fundamentada como prática discursiva de produção textual oral ao estabelecer um gênero oral com possibilidades de sua efetivação em sala de aula.

Compreendendo as propostas de produção em relação às incongruências reveladas pelas análises dos documentos oficiais que norteiam os processos de ensino para a disciplina de LP, refletimos que, 
Adriana Beloti

Cleber da Silva

Luz

132

em alguma medida, o trabalho com a produção textual oral em diversas disciplinas da Educação Básica podem refletir o trabalho realizado na disciplina de LP, uma vez que, se pensarmos que os professores de tais disciplinas não têm formação para trabalhar com aspectos relacionados com a linguagem, podemos pressupor que operam com as práticas que ainda estão interiorizadas de quando eram alunos e realizam as mesmas práticas no trato com a produção de textos em gêneros orais.

Ainda assim, a partir das análises, é necessário ressaltar que se a disciplina de LP, enquanto disciplina que tem social e formalmente atribuída a função de trabalhar a produção de textos, não tem uma concepção formada de maneira adequada para as práticas de produção textual oral, sobretudo pelos professores de tal disciplina terem formação específica para ensinar e trabalhar com essas práticas, é dificultoso às demais disciplinas operar com essas práticas, se não têm embasamento teórico-metodológico para atuar nas salas de aulas. Isso acarreta, de acordo com Antunes (2003), na falta de generalidade de oportunidades de se abordar os gêneros orais com foco na interação social, que podem envolver as situações várias do falar em público.

Destarte, neste trabalho, foi possível observar que, nas práticas com os textos orais na sala de aula, predomina a concepção de atividade oral, quase em concomitância com a de texto oral como organizador de ideias. A concepção de prática discursiva de produção textual oral, ainda que compreendida como a adequada, não tem espaço nas demais disciplinas, aparecendo apenas em duas propostas das 59 analisadas. Assim, compreendemos que há a necessidade de discussão e proposição de trabalhos que sistematizem as práticas discursivas de produção textual oral, a fim de modificar esse cenário, tanto na disciplina de LP, quanto nas demais disciplinas da Educação Básica.

\section{REFERÊNCIAS}

ANTUNES, I. Aula de português: encontro e interação. São Paulo: Parábola Editorial, 2003.

ALMEIDA, L. M. A. Fronteiras da globalização - Geografia. 2. ed. São Paulo: Ática, 2013. 
BAKHTIN, M. Estética da criação verbal. Trad. Paulo Bezerra. 6.e.d. São Paulo: WMF Martins Fontes, 2011.

BAUMGÄRTNER, C. T. Grupo de estudos de língua portuguesa GELP: uma experiência de formação continuada de professores com focos em gêneros orais e ensino. In: BUENO, L.; COSTA-HÜBES, T. C. (Org.). Gêneros orais no ensino. Campinas: Mercado de Letras, 2015, p. 91-115.

BRASIL. Secretaria de Educação Fundamental. Parâmetros Curriculares Nacionais: Terceiro e quarto ciclos do Ensino Fundamental - Língua Portuguesa, área de linguagens, códigos e suas tecnologias. Brasília: MEC/ SEF. 1998.

A produção textual de gêneros orais

BRASIL. Secretaria de Educação Fundamental. Parâmetros Curriculares Nacionais: Ensino Médio - Língua Portuguesa, área de linguagens, códigos e suas tecnologias. Brasília: MEC/ SEF. 2000.

DORETTO, S. A.; BELOTI, A. Concepções de linguagem e conceitos correlatos: a influência no trato da língua e da linguagem. Revista Encontros de Vista. 8. ed. 2011, p.89-103.

FIAD, R. S.; MAYRINK-SABINSON, M. L. T. A escrita como trabalho. In: MARTINS, M. H. (Org.). Questões de linguagem. 4. ed. São Paulo: Contexto, 1991. p. 54-63.

FONSECA, M. R. M. Química: ensino médio. 2. ed. São Paulo: Ática, 2016.

GERALDI, J. W. Portos de passagem. 4.ed. São Paulo: Martins Fontes, 1997.

LINHARES, S. Biologia hoje. 3. ed. São Paulo: Ática, 2016.

MARCUSCHI, L. A; DIONISIO, A. P. Fala e escrita. Belo Horizonte: Autêntica, 2007.

MARCUSCHI, L. A. Produção Textual: análise de gêneros e compreensão. São Paulo: Parábola Editorial, 2008. 
MENEGASSI, R. J. Conceitos bakhtinianos na prova de redação. In: Línguas \& Letras. Universidade Estadual do Oeste do Paraná. Campus de Cascavel. Centro de Educação, Comunicação e Artes. v.1, n.1 (2000). Cascavel: EDUNIOESTE, 2011.p. 99-119.

A escrita como trabalho em sala de aula. In: JORDÃo, C. M.

Adriana Beloti

Cleber da Silva

Luz

134

RAIMO, L. C. F. D. D.; BURACH, C. M. Oralidade ou oralização da escrita? Uma análise do livro didático letramento e alfabetização. Caderno Seminal Digital, ano 22. M. 26, jul/dez, 2016.

SILVA, C. C. Caracterização dos Comandos de produção textual da prova de redação da UEM. 2018. (Dissertação) - Programa de Pós-Graduação em Letras, Universidade Estadual de Maringá, Maringá, 2018.

TRAVAGLIA, J. C. [et al]. Gêneros orais - conceituação e caracterização. Anais do SILEL. Volume 3, Número 1. Uberlândia: EDUFU, 2013.

VASCONCELOS, J. A. Reflexões: filosofia e cotidiano - ensino médio. 1. ed. São Paulo: Edições SM, 2016.

VOLÓCHINOV, V. N./ BAKHTIN, M. Discurso na vida e discurso na arte: (sobre a poética sociológica). Tradução de Carlos Alberto Faraco e Cristóvão Tezza [para fins didáticos].1926. Versão da língua inglesa de I. R. Titunik a partir do original russo.

YAMAMOTO, K. Física para o ensino médio 1. 3. ed. São Paulo: Saraiva, 2013. 